doi: $10.2306 /$ scienceasia1513-1874.2014.40.016

\title{
Identification of phosphate-solubilizing fungi from the asparagus rhizosphere as antagonists of the root and crown rot pathogen Fusarium oxysporum
}

\author{
Samaporn Ruangsanka \\ Faculty of Science and Technology, Kanchanaburi Rajabhat University, Kanchanaburi 71190 Thailand \\ e-mail: samako@yahoo.com
}

Received 25 Jan 2013

Accepted 22 Dec 2013

\begin{abstract}
Identification of phosphate solubilizing fungi in the root zone of asparagus that can inhibit the growth of root and crown rot pathogen (Fusarium oxysporum) is important for the development of bio-fertilizer and bio-control strategies for organic production of asparagus. This study aimed to identify fungi with the ability to solubilize phosphate and inhibit the growth of $F$. oxysporum in vitro. Twenty five soil samples were collected from the asparagus rhizosphere in the planting areas of Dan Ma Kham Tea district, Kanchanaburi province, Thailand. A total of 59 fungi that could solubilize phosphate in Pikovskaya medium were isolated from 25 soil samples. Fourteen out of 59 fungal isolates were further screened and four isolates were selected. These isolates were tested for growth inhibition of $F$. oxysporum. One isolate was identified as Penicillium oxalicum and had the highest phosphate solubilizing ability (556 mg P/l). Another isolate was identified as Aspergillus niger and had the highest pathogen inhibition percentage (64\%). These isolates are promising for the development of bio-fertilizer and bio-control of $F$. oxysporum for organic production of asparagus.
\end{abstract}

KEYWORDS: biofertilizer, bio-control, organic production, pathogen inhibition

\section{INTRODUCTION}

Asparagus (Asparagus officinalis L.), an important vegetable worldwide ${ }^{1}$, is produced in Thailand for local consumption and export. The largest growing area of asparagus in Thailand is in Dan Ma Kham Tea district, Kanchanaburi, covering 211 ha.

To attain export quality, the crop requires intensive care and the application of chemical fertilizers, growth regulators, and pesticides. These practices are harmful to health of growers and consumers and result in high production cost and environmental deterioration. Agronomic practices that promote healthy plants, increase resistance to plant diseases, and reduce the application of chemical fertilizers, growth regulators, and pesticides are worth exploring.

Phosphate deficiency is common in agricultural soils and high input of phosphate fertilizer is required. To reduce phosphate fertilizer, bio-fertilizers such as phosphate solubilizing microorganisms (PSM) can be used. Microbially mediated solubilization of insoluble phosphates through release of organic acids is often combined with production of other metabolites, which take part in biological control against soilborne phy- topathogens ${ }^{2}$. The microorganisms favour to colonize the plant rhizosphere ${ }^{2}$. The bio-fertilizers of phosphate supplied by using PSM have been developed for sustainable agriculture.

Root and crown rot disease caused by $F$. oxysporum constitute a major problem during asparagus production ${ }^{1}$. The symptoms of the disease are difficult to detect at early growth stages. Once it is detected at late growth stages, the disease has become more severe and can kill the plants, causing low population density of the crop and low productivity.

Biological control using indigenous microorganisms of plant rhizosphere that can effectively inhibit soil pathogens benefit plant protection. The association between asparagus and beneficial microorganisms has not been studied. This study aims to identify fungi isolates that are effective in solubilizing $\mathrm{P}$ in growth medium and suppressing $F$. oxysporum in vitro. The objective of this study was to select the phosphate solubilizing fungi that can inhibit the growth of $F$. oxysporum in asparagus rhizosphere. The obtained information will be useful for improving sustainable management to produce healthy asparagus at low cost and without contaminating the environment. 
Table 1 Soil $\mathrm{pH}$, soil moisture content, total $\mathrm{P}$ and soluble $\mathrm{P}$ in soil samples collected from different asparagus plantations in Dan Ma Kham Tea district, Kanchanaburi!

\begin{tabular}{lcccc}
\hline Plantation & $\mathrm{pH}$ & $\begin{array}{c}\text { Moisture } \\
\text { content }(\%)\end{array}$ & $\begin{array}{c}\text { Total } \mathrm{P}_{2} \mathrm{O}_{5} \\
(\mathrm{mg} / \mathrm{kg})\end{array}$ & $\begin{array}{c}\text { Soluble } \mathrm{P}_{2} \mathrm{O}_{5} \\
(\mathrm{mg} / \mathrm{kg})\end{array}$ \\
\hline $\mathrm{A}$ & $6.6^{\mathrm{c}}$ & $12.7^{\mathrm{d}}$ & $0.24^{\mathrm{cd}}$ & $0.05^{\mathrm{c}}$ \\
$\mathrm{B}$ & $6.6^{\mathrm{c}}$ & $11.2^{\mathrm{e}}$ & $0.21^{\mathrm{d}}$ & $0.04^{\mathrm{d}}$ \\
$\mathrm{C}$ & $6.7^{\mathrm{bc}}$ & $13.6^{\mathrm{c}}$ & $0.33^{\mathrm{ab}}$ & $0.08^{\mathrm{a}}$ \\
$\mathrm{D}$ & $6.9^{\mathrm{ab}}$ & $16.1^{\mathrm{b}}$ & $0.34^{\mathrm{a}}$ & $0.08^{\mathrm{a}}$ \\
$\mathrm{E}$ & $7.0^{\mathrm{a}}$ & $17.5^{\mathrm{a}}$ & $0.28^{\mathrm{bc}}$ & $0.06^{\mathrm{b}}$ \\
\hline
\end{tabular}

$\dagger$ Means in the same column with the same letter(s) are not statistically different at 0.05 probability level by DMRT.

\section{MATERIALS AND METHODS}

\section{Soil samples}

The study was conducted at the Applied Biology Program, Faculty of Science and Technology, Kanchanaburi Rajabhat University, Kanchanaburi province, Thailand. Five asparagus plantations in Dan Ma Kham Tea district, Kanchanaburi were randomly chosen for this study in February in the dry season 2011. Five soil samples were taken from each plantation, and there were 25 subsoil samples totally for soil analysis and fungal isolation.

Soil properties were evaluated for $\mathrm{pH}$, moisture content, total $\mathrm{P}$ and available $\mathrm{P}$ by the Chemistry Program, Kanchanaburi Rajabhat University (Table 1). The method for $\mathrm{P}$ analysis has been described ${ }^{3}$. Five replications were used for each plantation, and five plantations for five soil samples were then designated as $\mathrm{A}, \mathrm{B}, \mathrm{C}, \mathrm{D}$, and $\mathrm{E}$.

\section{Fungi isolation}

Phosphate solubilizing fungi (PSF) were isolated from 25 subsamples of the soils using selective media, Pikovskaya medium (PVK). A total of 59 fungi were originally obtained and were screened at the first stage of the study. After screening, 14 fungal isolates were obtained, which were further screened based on Halo:colony ratio (radiant of clear zone/radiant of colony) giving four isolates for further evaluation.

\section{Test for $\mathrm{pH}$ and phosphate solubilization}

The most 3 active PSF were analysed for $\mathrm{pH}$ and phosphate solubilization after incubation for 4 days in PVK medium at $30^{\circ} \mathrm{C} 150 \mathrm{rpm}$. The culture broth was filtered by Whatman filter paper No. 42 . Following the ascorbic acid method, the combined reagent containing $5 \mathrm{~N} \mathrm{H}_{2} \mathrm{SO}_{4}$, antimony potassium tartrate, ammonium molybdate, and $0.1 \mathrm{M}$ ascorbic acid was added to the clear filtrate to develop blue colour for OD-880 measurement. The soluble P was calculated by interpolation in a standard curve ${ }^{4}$.

\section{Test for $\boldsymbol{F}$. oxysporum inhibition of growth}

Four PSFs were also tested for inhibition of $F$. oxysporum growth by dual culture on PDA in Petri dishes ${ }^{5}$. Briefly, the tested fungi and fungal pathogen were separately cultured by spot inoculation in PDA for 7 days. The growth medium with the fungi and fungal pathogen were cut at the same size at the edge of the colony and placed at the centre of fresh PDA medium $5 \mathrm{~cm}$ apart. The treatments were replicated twice. The dual cultures were incubated at $25-30{ }^{\circ} \mathrm{C}$ for 7 days. After 7 days after incubation, the diameters of colonies of both phosphate solubilizing fungi and fungal pathogen were measured and percentage of growth reduction of the pathogen calculated using

$$
\% \text { growth reduction }=\frac{D_{\mathrm{c}}-D_{\mathrm{s}}}{D_{\mathrm{c}}} \times 100 \%,
$$

where $D_{\text {c }}$ is colony diameter of $F$. oxysporum (control) and $D_{\mathrm{s}}$ is colony diameter of $F$. oxysporum inoculated with tested fungi. This calculation is equivalent to inhibition percentage of the radial growth as described previously ${ }^{5}$.

\section{Statistical analysis}

The data for soluble phosphorus (mg P/l) and the pathogen growth reduction (\%) were analysed statistically according to a completely randomized design, and the means were separated at 0.05 probability level by Duncan's multiple range test. The highest potential fungi were identified by gene sequencing at the BIOTEC, National Science and Technology Development Agency (NSTDA) Thailand.

\section{RESULTS AND DISCUSSION}

\section{Soil properties}

Significant differences for values of $\mathrm{pH}$ ranging from 6.6-7.0 were observed among five asparagus plantations (Table 1). The soils were neural to slightly acidic and suitable for growth and yield of asparagus. Soil moisture contents were also significantly different ranging from 11-18\%. Differences in soil moisture contents would be largely due to differences in water management among plantations because soil sampling was carried out in the dry period. Irrigation in the dry period is necessary for optimum growth and yield of vegetable crops including asparagus.

$\mathrm{P}$ values are expressed as $\mathrm{mg}$ of $\mathrm{P}_{2} \mathrm{O}_{5}$ per $\mathrm{kg}$ of soil, and the conversion factor for $\mathrm{P}$ is 0.44 . There were significant differences among plantations for 
Table 2 Growth character and halo:colony ratio for 14 isolates of $\mathrm{P}$ solubilizing fungi extracted from 25 soil samples!

\begin{tabular}{lcc}
\hline Isolate & $\begin{array}{c}\text { Growth } \\
\text { character }\end{array}$ & $\begin{array}{c}\text { Halo:colony } \\
\text { ratio }\end{array}$ \\
\hline A1I2 & Slow & $1.46^{\mathrm{e}}$ \\
A4I9 & Rapid & $2.16^{\mathrm{c}}$ \\
A4I10 & Slow & $2.16^{\mathrm{c}}$ \\
B1I2 & Rapid & $1.41^{\mathrm{e}}$ \\
B1I54 & Rapid & $1.86^{\mathrm{d}}$ \\
C1I1 & Rapid & $1.17^{\mathrm{e}}$ \\
C2I34 & Slow & $2.10^{\mathrm{cd}}$ \\
C3I42 & Rapid & $2.96^{\mathrm{a}}$ \\
C3I43 & Rapid & $1.17^{\mathrm{e}}$ \\
D3I5 & Slow & $1.98^{\mathrm{cd}}$ \\
D3I8 & Slow & $2.05^{\mathrm{cd}}$ \\
D4I11 & Rapid & $2.63^{\mathrm{b}}$ \\
D4I12 & Slow & $2.11^{\mathrm{cd}}$ \\
E5I15 & Slow & $1.90^{\mathrm{cd}}$ \\
\hline
\end{tabular}

${ }^{\dagger}$ Means in the same column with letter(s) are not statistically different at 0.05 probability level by DMRT.

total $\mathrm{P}$ and soluble $\mathrm{P}$. Total $\mathrm{P}$ values ranged from $0.21-$ $0.34 \mathrm{mg} / \mathrm{kg}$, whereas soluble $\mathrm{P}$ values ranged from $0.04-0.08 \mathrm{mg} / \mathrm{kg}$.

Soil test critical values are generally used to determine nutrient deficiency of crops. Nutrients with values exceeding critical values are not necessary for commercial production of the crops because high values contribute less to yield increase. For pasture, soil test critical value of $P$ is $15 \mathrm{mg} / \mathrm{kg}$ soil ${ }^{6}$. Unfortunately, critical value of $\mathrm{P}$ is not available for asparagus. Asparagus growth however increases linearly in the $\mathrm{P}$ range of $20-160 \mathrm{mg} / \mathrm{kg}^{7}$. Marketable yields were not affected by $\mathrm{P}$ fertilization in either year, suggesting unmodified soil at the test site contained adequate $\mathrm{P}$ for asparagus production (about $160 \mathrm{mg}$ Mehlich III extractable P per kg) ${ }^{8}$. The critical value for asparagus is therefore much higher than that for pasture, and the crop in this study was highly deficient for P.

Chemical fertilizers are not used for organic asparagus production in Thailand ${ }^{9}$. Hence, organic fertilizers and biofertilizers are important to produce organic asparagus.

\section{Growth character in medium and $F$. oxysporum inhibition}

At initial phase, total numbers of 59 indigenous fungi of asparagus rhizosphere were isolated from 25 soil samples, and $14 \mathrm{P}$ solubilizing fungi were selected at this phase (Table 2). These isolates were further screened for $\mathrm{P}$ solubilizing property based on rapid growth and halo:colony ratio against $F$. oxysporum. Based on these criteria, four isolates (C3I42, A4I9, D3I8, and B1I54) were selected for further evaluation.

\section{$P$ solubilization and reduction of $F$. oxysporum growth}

Further evaluation showed that the isolate C3I42 had the highest halo:colony ratio (2.96) and soluble $\mathrm{P}$ (556 mg P/l) followed by the isolate A4I9 (Table 3). These isolates, however, had low $\mathrm{pH}$ and percentage reduction of pathogen growth. The isolate B1I54 had the highest $\mathrm{pH}(6.04)$ and percentage reduction of pathogen growth $(64 \%)$, but it had the lowest halo:colony ratio and soluble P. The isolate D3I8 had rather high halo:colony ratio and $\mathrm{pH}$, but it had low soluble $\mathrm{P}$ and percentage reduction of pathogen growth.

The four isolates were later identified at the species level. C3I42 was identified as P. oxalicum, A4I9 was $P$. calidicanium, D3I8 was A. allahabadii, and B1I54 was A. niger (Table 4). Growth of P. oxalicum (isolate C3I42) and inhibition of $F$. oxysporum by isolate B1I54 are shown in Fig. 1. The growth of C3I42 was rapid as it appeared in large colonies after four days of incubation. It was also clear that black the colony of B1I54 inhibited the pink colony of F. oxysporum.

In this study, $P$. oxalicum (isolate C3I42) showed the highest solubilization of $\mathrm{P}$ in vitro but it had the lowest ability to suppress the growth of $F$. oxysporum. The results were consistent with previous findings showing that $P$. oxalicum from rhizosphere soil in Rajasthan State Mines and Minerals Limited (RSMML) could increase soluble P in Pikovskaya's medium $^{11}$, and the authors also found that inoculation of $P$. oxalicum together with rock phosphate could improve wheat and maize production in alkaline soil. Similarly, inoculation of other phosphate solubilizing micro-organisms such as Paenibacillus polymyxa and Bacillus megaterium var. phosphaticum could improve tomato growth and yield ${ }^{12}$. It is promising to use $P$. oxalicum as biofertilizer for improving asparagus productivity in organic farming systems.

In this study, A. niger (isolate B1I54) was most efficient in vitro for reduction of $F$. oxysporum growth, but it had low phosphate solubilizing ability. In previous investigations, A. niger was ineffective to inhibit $F$. oxysporum f. sp. lycopersici (Sacc.) W.C. Snyder and H.N. Hans $(\text { Fol. })^{5}$. However, Trichoderma was not found in the soil samples in this study. If the interaction between pathogens and antagonistic fungi is site-specific, A. niger is also a promising candidate for the development of biocontrol for organic aspara- 
Table 3 Halo:colony ratio, soluble $\mathrm{P}, \mathrm{pH}$, and \% reduction of pathogen growth as affected by four isolates of phosphate solubilizing fungi against $F$. oxysporum!

\begin{tabular}{lcccc}
\hline Isolate & Halo:colony ratio & Soluble $\mathrm{P}(\mathrm{mg} / \mathrm{l})$ & $\mathrm{pH}$ & Reduction of pathogen growth $(\%)$ \\
\hline C3I42 & $2.96 \pm 0.57^{\mathrm{a}}$ & $556.10 \pm 3.7^{\mathrm{a}}$ & $2.63 \pm 0.24^{\mathrm{d}}$ & $9.11 \pm 0.13^{\mathrm{c}}$ \\
A4I9 & $2.16 \pm 0.14^{\mathrm{b}}$ & $206.68 \pm 3.6^{\mathrm{b}}$ & $3.75 \pm 0.01^{\mathrm{c}}$ & $12.36 \pm 0.33^{\mathrm{b}}$ \\
D3I8 & $2.05 \pm 0.05^{\mathrm{b}}$ & $104.58 \pm 4.9^{\mathrm{c}}$ & $4.69 \pm 0.08^{\mathrm{b}}$ & $3.25 \pm 2.93^{\mathrm{d}}$ \\
B1I54 & $1.86 \pm 0.42^{\mathrm{b}}$ & $88.93 \pm 2.5^{\mathrm{d}}$ & $6.04 \pm 0.17^{\mathrm{a}}$ & $63.56 \pm 0.87^{\mathrm{a}}$ \\
\hline
\end{tabular}

${ }^{\dagger}$ Means in the same column with the same letter(s) are not statistically different at 0.05 probability level by Duncan's multiple range test (DMRT).

Table 4 Fungal identification of four fungal isolates using ITS1-4 region sequencing method!

\begin{tabular}{llcc}
\hline Sample Isolate & Fungal species & Similarity $(\%)$ & Note \\
\hline C3I42 & Penicillium oxalicum & 100 & Ref. 10 \\
A4I9 & Penicillium calidicanium & 98 & compared with CBS 112002 \\
D3I8 & Aspergillus allahabadii & 99 & compared with CBS 124597 \\
B1I54 & Aspergillus niger & 100 & compared with ATCC 64973 \\
\hline
\end{tabular}

${ }^{\dagger}$ CBS 112002, CBS 124579, and ATCC 64973 are the reference accession codes in NCBI (GenBank) nucleotide sequence database with the highest degree of similarity compared with the fungal strains in this study.

gus production. The results support previous findings and adds new information.

The research met the objective in identifying the fungi the ability to solubilize phosphate and to control the growth of $F$. oxysporum. Unfortunately, these abilities occurred in different species of fungi. This investigation was limited to conditions in vitro, and more studies under natural conditions in vivo are also required to confirm their ability and pathogenesis.

Acknowledgements: National Research Council of Thailand (NRCT) and Kanchanaburi Rajabhat University are gratefully acknowledged for providing research grant and research facilities. The BIOTEC and National Science and Technology Development Agency (NSTDA) Thailand are also acknowledged for their contribution to fungal identification.

\section{REFERENCES}

1. Baayen PR, van den Boogert PHJF, Bonants PJM, Poll JTK, Blok WJ, Waalwijk C (2000) Fusarium redolens f.sp. asparagi, causal agent of asparagus root rot, crown rot and spear rot. Eur J Plant Pathol 106, 907-12.

2. Vassilev N, Vassileva M, Nikolaeva I (2006) Simultaneous P-solubilizing and biocontrol activity of microorganisms: potentials and future trends. Appl Microbiol Biotechnol 71, 137-44.
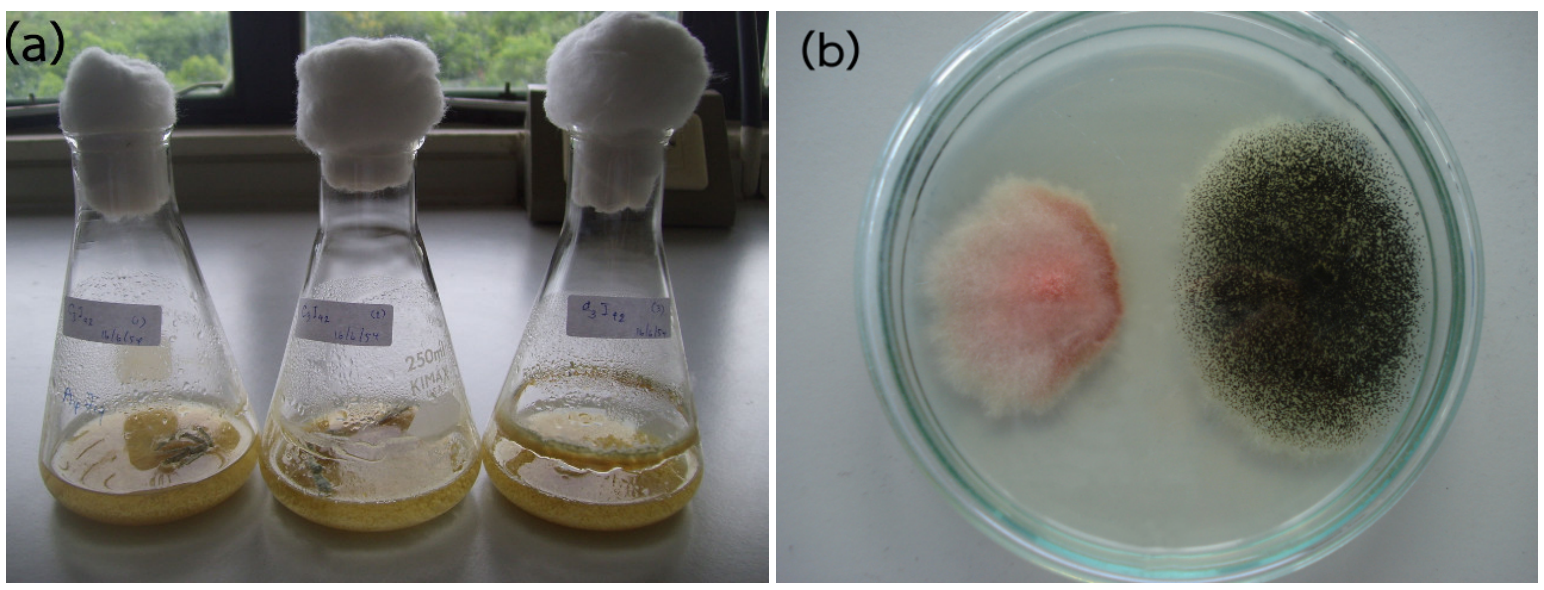

Fig. 1 (a) P. oxalicum isolate C3I42 in PVK broth for 4 days of incubation; (b) growth inhibition of $F$. oxysporum (pink colony) by isolate B1I54 (black colony). 
3. Richardson AE, Barea JM, McNeill AM, PrigentCombaret C (2009) Acquisition of phosphorus and nitrogen in the rhizosphere and plant growth promotion by microorganisms. Plant Soil 321, 305-39.

4. Ketterings QM, Barney P (2010) Phosphorus soil testing methods. Agronomy Fact Sheet \#15, Cornell Univ Cooperative Extension [Available at: http://nmsp.cals. cornell.edu/publications/factsheets/factsheet15.pdf].

5. Helrich K (1990) Official Methods of Analysis. Association of Official Analytical Chemists Inc., Arlington, VA, $\mathrm{p} 61$.

6. Mishra KK, Kumar A, Pandey KK (2010) RAPD based genetic diversity among different isolates of Fusarium oxysporum f. sp. lycopersici and their comparative biocontrol. World J Microbiol Biotechnol 26, 1079-85.

7. Gourley CJP, Melland AR, Waller RA, Awty IM, Smith AP, Peverill KI, Hannah MC (2007) Making Better Fertiliser Decisions for Grazed Pastures in Australia. Victorian Government Department of Primary Industries.

8. Vijay N, Kumar A, Bhoite A (2009) Influence of nitrogen, phosphorus and potassium fertilizer on biochemical content of Asparagus racemosus (Willd.) root tubers. Res J Environ Sci 3, 285-91.

9. Sommerville DW, Whalen JK (2005) Phosphorus fertilization and asparagus yield during establishment years. Can J Plant Sci 85, 687-92.

10. Lorlowhakarn S, Piyatiratitivorakul S, Cherdshewasart W (2008) Organic asparagus production as a case study for implementation of the national strategies for organic agriculture in Thailand. Thai J Agr Sci 41, 63-74.

11. Umemoto $\mathrm{S}$, Odake $\mathrm{M}$, Takeuchi $\mathrm{T}$, Yoshida $\mathrm{S}$, Tsushima S, Koitabashi M (2009) Blue mold of tomato caused by Penicillium oxalicum in Japan. J Gen Plant Pathol 75, 399-400.

12. Singh H, Reddy SM (2011) Effect of inoculation with phosphate solubilizing fungus on growth and nutrient uptake of wheat and maize plants with rock phosphate in alkaline soils. Eur J Soil Biol 47, 30-4. 